\title{
E-ISSN: 2746-8607
}

http://jurnal.unipasby.ac.id/index.php/jsbr

\section{ANALISIS PERBANDINGAN PERHITUNGAN HARGA POKOK PRODUKSI MENGGUNAKAN METODE FULL COSTING DAN VARIABLE COSTING UNTUK MENENTUKAN LABA BERSIH PT. BHASKARA MADYA JAYA}

\author{
Nia Agustin Pratama1, Teguh Purwanto \\ Universitas PGRI Adi Buana Surabaya ${ }^{1,2}$ \\ niahermoso@gmail.com
}

\section{ABSTRACT}

With the addition of profits, the company can pay all costs that are sacrificed, so that the company's operational activities are guaranteed and can run well. The problems examined in this study are intended to find out how the comparison of recording costs using the full costing method and variable costing affects the net profit of PT Bhaskara Madya Jaya. Both of these methods simultaneously involve raw materials, direct labor costs and factory overhead costs. What distinguishes the full costing method using fixed factory overhead loads and variable, if the variable costing only adds to the variable overhead load. Production costs that are not included in the raw material and direct labor costs are the overhead of the manufacturing plant itself. Descriptive method with a quantitative approach is the model of this research. With the use of saturated sampling. Documentation is a data collection technique that researchers use. The results of the study and details obtained by comparing the full costing method and variable costing. In detailing the cost of production, the full costing method produced a greater than the costing variable, this is due to the full costing method adding all the elements of costs, variable costs or fixed costs. Then from the results of the breakdown of net income, using the full costing method, the nominal profit is found to be far less than using the variable costing method.

Keyword: Full Costing, Variable Costing, Net Profit

\section{PENDAHULUAN}

Aktivitas di bidang perkembangan ekonomi yang memiliki kontribusi penting dalam pelorehan acuan pembangunan, guna menjangkau terealisasinya tujuan pengembangan nasional, jasa konstruksi biasanya dilakukan sebuah perencanaan selaras. Besarnya beban yang harus dikorbankan, desain bangunan dan imbas lain yang akan ditimbulkan saat pembangunan konstruksi. Hal ini memiliki keterterkaitian dengan metode penentuan. Pembiayaan, imbas lingkungan, kenyamanan lingkungan ketersiapan material, logistic, ketidaknyamanan publik terkait dengan aktivitas konstruksi, persediaan dokumen tender, dan sebagainya.juga andil mempengaruhi suksesnya sebuah bangunan dan juga tidak akan lepas dengan perangkaan yang baik dan matang.

Keunikan yang khas yang dimiliki perusahaan jasa konstruksi yaitu, dimana prosedur implementasi proyek tidak terselesaikan semuanya dalam satu waktu atau tidak semua periode akuntansi di kerjakan dimulai dari awal tahun. Hal ini mempengaruhi munculnya beberapa metode yang digunakan perusahaan untuk mengakui pendapatannya yang merupakan salah satu komponen terbentuknya laba. Laba adalah sasaran utama didirikannya suatu perusahaan. Karena pada umunya suatu perusahaan ingin melakukan pengorbanan yang minimal dan menghasilkan keuntunngan yang maksimal guna membiayai seluruh kegiatan aktivitas perusahaan, dengan keuntungan ini perusahaan berkembang dengan menggunakan kemampuan lebih besar untuk berkembang.

Banyak metode yang akan diterapkan untuk mendapatkan laba yaitu dengan menekan biaya proyek konstruksi yang akan dikeluarkan perusahaan. Biaya memegang penting dalam keberlangsungan penyelenggaraan proyek. Biaya adalah merupakan pengorbanan atau beban yang dikeluarkan untuk mencapai suatu tujuan yang bersifat khusus yang biasanya diukur dengan satuan mata uang. Dalam pelaksanaan suatu proyek konstruksi pada dasarnya pasti akan mengeluarkn macam macam biaya dalam prakteknya dan salah satunya adalah biaya konstruksi. Secara teori pada dasarnya biaya proyek konstruksi sama halnya denga biaya produksi, hal ini didukung denga teori Hansen Seng (2017, 144-153), ditinjau dari perspektif kontraktor, maka biaya proyek konstruksi diwujudkan dalam nilai kontrak pekerjaan konstruksi tersebut yang merupakan pengorbanan yang mencerminkan total beban pekerjaan konstruksi yang harus dibiayai oleh pemilik proyek kepada kontraktor atas pekerjaan yang telah dilakukan.

Tinggi rendahnya laba dipengaruhi oleh harga penjualan, lalu harga pokok produksi mendasari persentase tinggi rendahnya harga jual. keputusan manajerial pada penentuan harga jual dipengaruhi pada ditentukannya harga pokok produksi, hal ini dapat mngakibatkan pada laba yang rendah atau bahkan hingga kemungkinan kerugian. Maka dari itu pengendalian terhadap biaya untuk menggapai laba yang diinginkan oleh perusahaan merupakan salah satu 


\section{Journal of Sustainability Business Research (JSBR) \\ Vol-1,Issue-1,Desember (JSBR)}

\section{E-ISSN: 2746-8607}

http://jurnal.unipasby.ac.id/index.php/jsbr

unsur yang penting. Perusahaan akan mengorbankan beban biaya dari mulai pembuatan hingga memperoleh produk jadi yang siap dijual di aktivitas produksinya. Biaya bahan baku, biaya tenaga kerja langsung, serta biaya overhead pabrik merupakan data yang dikalkulasikan pada penentuan harga pokok produksi

teknik full costing serta metode variable costing dapat dimanfaatkan dalam penentuan harga pokok produksi. Jika memakai teknik full costing semua beban biaya dikalkulasikan baik yaitu bersifat tetap ataupun variabel. Variable costing merupakan teknik akuntansi manajemen guna menciptakan biaya produk. Yang menjadi keuntungan menggunakan teknik variable costing yakni untuk perantara pengendali biaya yang harus dikeluarkan, karena metode ini menyemaikan semua biaya yang digolongkan dalam biaya tetap digolongkan tersendiri pada satu golongan tidak di campur dengan biaya biaya lainnya, ditujukan agar memudahkan di pihak manajer pada memfokuskan pokok perhatian pada perlakuan biaya tetap

Berdasarkan latar belakang diatas maka peneliti melaksanakan studi dengan judul "Pengaruh Biaya Proyek Konstruksi Terhadap Laba Bersih Tahun 2016-2018 PT Bhaskara Madya Jaya".

\section{RUMUSAN MASALAH}

Didasarkan uraian latar belakang sebelumnya, didapatkan rumusan masalah pada penelitian antara lain:

1. Apakah perhitungan harga pokok produksi dengan memakai teknik full costing mempengaruhi laba bersih perusahaan jasa konstruksi PT Bhaskara Madya Jaya?

2. Bagaimanakah perhitungan harga pokok produksi dengan memamakai teknik variabel costing menmpengaruhi laba bersih perusahaan jasa konstruksi PT Bhaskara Madya Jaya?

3. Bagaimana perbandingan perhitungan harga pokok produksi dengan memakai teknik full costing serta metode variabel costing mempengaruhi laba bersih perusahaan jasa konstruksi PT Bhaskara Madya Jaya?

\section{TINJAUAN PUSTAKA DAN HIPOTESIS}

\section{Akuntansi Biaya}

Menurut Mulyadi (2010:7) "Akuntansi biaya merupakan mencatat, pengelompokkan, perincian, serta menyajikan biaya pengolahan serta jual produk maupun jasa menggunakan metode tertentu. Akuntasi biaya sangat penting digunakan karena informasinya dibutuhkan oleh manajemen

\section{Biaya Produksi}

Menurut Mulyadi (1995:14), biaya produksi memiliki arti keseluruhan biaya dalam mengolah bahan mentah menjadi barang yang bisa digunakan serta dapat untuk dilakukan penjualan. Keseluruhan biaya yang dipakai guna memproduksi bahan baku termasuk biaya pegawai dan biaya overhead jika dikalkulasikan jumlahnya lebih tinggi dibandingkan dengan jenis biaya lain merupakan beban yang harus di korbankan pada proses produksi.

\section{Harga pokok produksi}

menurut Supriyono (2013) harga pokok merupakan total biaya yang dikalkulasikan dengan bentuk mata uang yang dijadikan transaksi aau bisa diartikan sebagai keseluruhan biaya yang dikelurakanoleh perusahaan agar dapat menghasilakn sebuah produk

\section{Metode Full Costing}

cara yang diperuntukkan untuk kalkulasi HPP, yang dibebankan kepada seluruh beban produksi yang meliputi variabel berkarakter tetap maupun variabel yang dihasilkan suatu perusahaan.

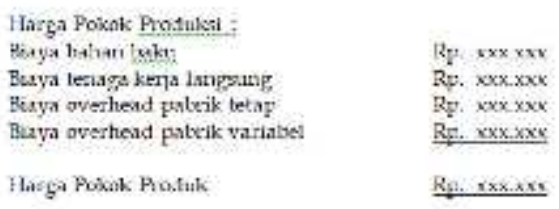




\section{Journal of Sustainability Business Research (JSBR)}

Vol-1,Issue-1,Desember (JSBR)

\section{E-ISSN: 2746-8607}

http://jurnal.unipasby.ac.id/index.php/jsbr

PENYAJIAN LAPORAN LABA RUGI

\section{Laporan Laba-Rugi}

(Metode Full Costing )

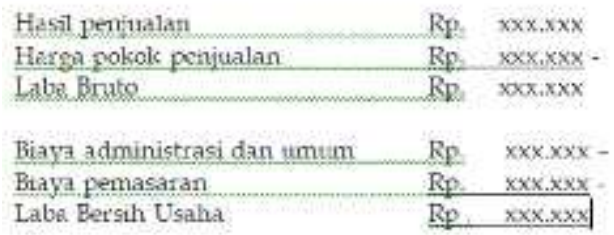

\section{Metode Variable Costing}

suatu cara penjumlahan biaya pokok dalam memproduksi yang mengakalkulasikan biaya pengolahan variabel saja.

Dapat disebut juga dengan istilah biaya langsungjuga dengan istilah biaya langsung

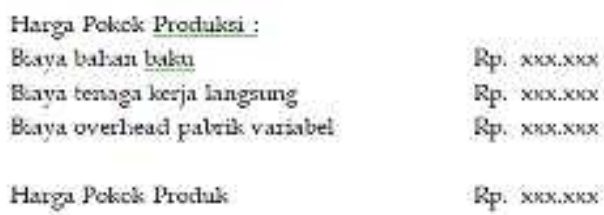

6. Konstruksi

Konstruksi yaitu aktivitas dalam membangun infrastruktur pada suatu area yang fungsional dan ekonomis agar dalam biaya menjasi relative efisien dan efektif namun konstruksi harus kuat serta awet agar biaya pemeliharaan tidak banyak

\section{Laba Bersih}

Laba adalah semua transaksi yang mengahasilkanpeningkatan modal (aktiva bersih) yang berawal dari dari perusahaan, serta peristiwa yang memiliki nilai keuntungan dalam 1 periode, atau transaksi yang timbul dari perolehan (revenue) atau investasi pemegang (Baridwan, 1992: 55).

\section{Kerangka Konseptual}




\section{Journal of Sustainability Business Research (JSBR)}

Vol-1,Issue-1,Desember (JSBR)

\section{E-ISSN: 2746-8607}

http://jurnal.unipasby.ac.id/index.php/jsbr

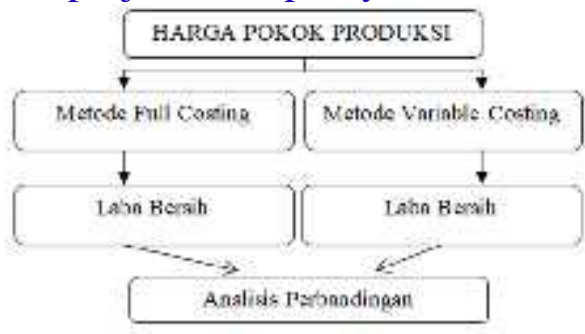

\section{HIPOTESIS}

Berdasarkan uraian yang telah diajukanlalu peneliti berasumsi bahwa perkalkulasian harga pokok produksi dengan memakai teknik Variable Costing mendapatan laba lebih tinggi daripada memakai perhitungan Full Costing.

\section{POPULASI, SAMPEL SERTA TEKNIK PENGAMBILAN SAMPEL}

\section{POPULASI}

Populasi merupakan seluruh perhitungan baik nilai I pengkalkulasian ataupun penukaran, kuantitatif ataupun kualitatif, dari spesifik kusus perihal segerombolan target yang rinci serta spesifik,Husaini Usman (2016 : 181).

Populasi dalam penelitian ini Laporan Laba Rugi tahun 2018 PT Bhaskara Madya Jaya

\section{SAMPEL}

Sugiyono (2017 : 81) mengatakan yang dimaksud sampel yakni "Pada studi kuantitatif sampel merupakan sekumpulan golongan yang akan diteliti dan spesifikasi yang ditujukan oleh populasi tersebut." Menggunakan sampel yang spesifik sangat diperlukan guna memahami banyaknya sampel yang hendak dijangkau pada melakukan penelitian. Lalu seluruh jumlah sampel yang telah dirujuk itu biasanya dikalkulasikan dengan statistika maupun taksiran penelitian.

Sampel yang dipakai pada penelitian ini merupakan Laporan Laba Rugi tahun 2018 PT Bhaskara Madya Jaya.

\section{TEKNIK PENGAMBILAN SAMPEL}

Sugiyono (2016:81) bertutur metode sampling ialah metode pengutipan sampel, guna memutuskan sampel yang hendak dirujuk pada studi ditemukan bermacam metode sampling.

Metode non probability sampling adalah metode yang dipakai untuk studi ini, teknik sampling yang dirujuk oleh peneliti adalah dengan fungsi teknik sampel jenuh. Menurut Sugiyono (2001:61) sampel jenuh merupakan metode pemilihan sampel jika seluruh unsur populasi dipakai untuk sampel.

\section{METODE}

studi ini memakai metode deskriptif dan analisa data secara kuantitatif. Serta sampel yang dipakai adalah sumber data keuangan Laporan Laba Rugi PT Bhaskara Madya Jaya. Data dihimpun dengan cara dokumentasii

HASIL

Perhitungan Harga Pokok Produksi Dengan Metode Full Costing: 
Journal of Sustainability Business Research (JSBR)

Vol-1,Issue-1,Desember (JSBR)

\section{E-ISSN: 2746-8607}

http://jurnal.unipasby.ac.id/index.php/jsbr

\begin{tabular}{|c|c|}
\hline \multicolumn{2}{|c|}{$\begin{array}{c}\text { Rincian Perhitungan barga pokok prodolksi Metode } \\
\text { Full Costing PT BHASKARA MADYA JAYA Tahein } \\
\text { 2U1' }\end{array}$} \\
\hline Keterangan & Tahun $20[8(\mathbb{R p})$ \\
\hline Baiaya Bahwa Baku. & 90359206 \\
\hline Banya Tenaza Kerga Langourg & 812492175 \\
\hline Bisya Overtead Farbrik & \\
\hline Bsaya Overbead Farbrik Tertnp & 884320735 \\
\hline Biaya Overbead Parbrik Varinbel & 251416262 \\
\hline IIarga Pokok Frodaksi & 2942.176999 \\
\hline
\end{tabular}

Berdasarkan tabel tersebut bisa dikemukakan bila keseluruhan biaya produksi PT BHASKARA MADYA JAYA tahun 2018 yaitu sebesar Rp 2.942.176.999

\section{Hasil Perhitungan Laba Bersih Dengan Metode Full Costing:}

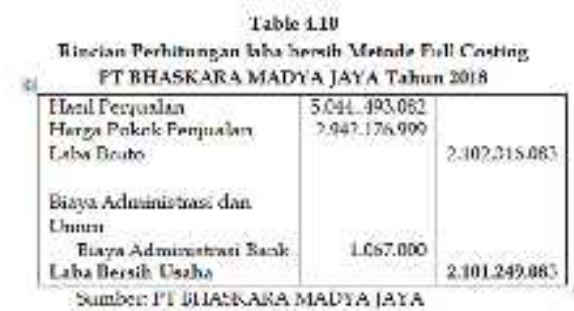

menurut tabel 4.10 bisa disebutkan jika seluruh laba bersih PT BHASKARA MADYA JAYA dengan memakai teknik full costing selama periode 2018 yaitu sejumlah Rp 2.101.249.083

Hasil Perhitungan Harga Pokok Produksi Menggunakan Teknik Variabel Costing:

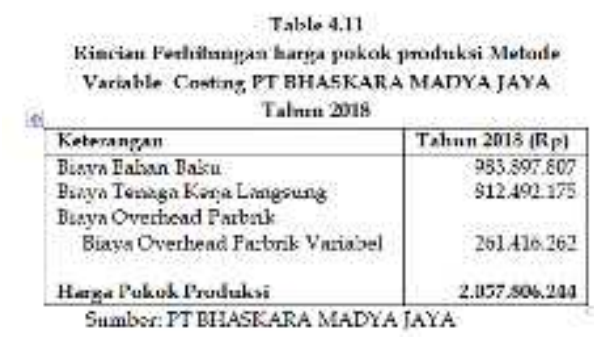

Menurut tabel 4.11 bisa diketahui jika jumlah biaya produksi PT BHASKARA MADYA JAYA selama tahun 2018 yaitu sebesar Rp 2.057.806.244

\section{Hasil Perhitungan Laba Bersih Dengan Teknik Variabel Costing:}

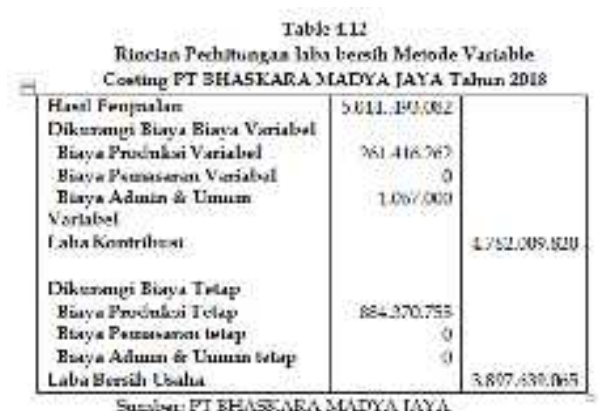

Menurut tabel 4.12 bisa diketahui jika keseluruhan laba bersih PT BHASKARA MADYA JAYA dengan memanfaatkan metode variabel costing selama tahun 2018 yaitu sebesar Rp 3.897.639.065 
Journal of Sustainability Business Research (JSBR)

Vol-1,Issue-1,Desember (JSBR)

E-ISSN: 2746-8607

http://jurnal.unipasby.ac.id/index.php/jsbr

\section{Hasil Perbandingan Perhitungan Harga Pokok Produksi Dan Laba Bersih Metode Full Costing Serta Metode Variable Costing PT BHASKARA MADYA JAYA Tahun 2018}

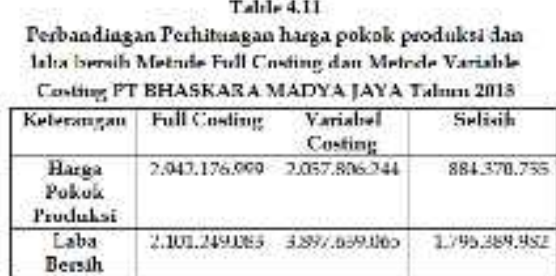

Berdasarkan tabel tersebut diperoleh perbedaan harga pokok produksi yakni sejumlah Rp.884.370.755. Pengkalkulasian kedua harga pokok produksi secara teknik full costing serta teknik variable costing mempunyai kharakteristik yang perpautan. harga pokok produksi dihasilkan lebih banyak menggunakan metode fuill costing daripada dengan teknik variable costing. Sebab disebabkkannya dengan memakai teknik full costing seluruh biaya dikalkulasi dengan gamblang, biaya overhead pabrik, biaya bahan baku,serta biaya tenaga kerja. Sedangkan pengkalkulasian harga pokok lebih rendah menggunakan teknik variable costing karena dalam biaya produksinya entitas tidak mengkalkulasi biaya overhead pabrik secara detil. Yang dilaksanakan pengkalkulasian oleh entitas ialah biaya bahan baku, biaya tenaga kerja serta biaya overhead pabrik yang semata-mata bercirikhas variable saja atau yang dianggap karateristiknya tidak menentu. Sebab itu, perengkalkulasian biaya produksi variable costing lebih sedikit daripada dengan memamkai teknik full costing.

Perbedaan laba bersih berdasarkan teknik full costing serta variabel costing sejumlah Rp. 1.796.389.982, ini disebab kan sebab teknik full costing masih melekat biaya overhead pabrik tetap.

\section{SIMPULAN}

Penelitian ini bermakna guna menjawab rumusan masalah, menurut nilai analisa serta pembahasan yang dilaksanakan penulis, bahwa hasil penelitian bisa disimpulkan :

1. Pengkalkulasian harga pokok produksi memanfaatkan teknik full costing pada entitas PT BHASKARA MADYA JAYA membuktikan bahwa harga pokok produksi sebesar Rp. 2.942.176.999 serta laba bersih Rp.2.101.249.083

2. pengkalkulasian harga pokok produksi memanfaatkan metode variabel costing pada PT Bhaskara Madya Jaya perusahaan mengeluarkan harga pokok yang lebih sedikit daripada teknik full costing yakni sejumlah Rp. 2.057.806.244 serta laba bersih Rp.3.897.639.065

3. Kedua variabel ini memiliki karakteristik perpautan perhitungan harga pokok produksi serta laba bersih ini dikarenakan perpautan munculnya pembenahan biaya mulai awal. Teknik full costing hendak membebankan seluruh BOP baik yang berciri tetap ataupun yang berciri variable, lalu jika teknik variable costing tidak mengkalkulasikan BOP tetap untuk biaya produksi. Peengkalkulasian kedua teknik tersebut terdapat perbedaan harga pokok produksi sejumlah Rp. 884.370 .755 serta laba bersih Rp. 1.796.389.982

\section{IMPLIKASI}

Berdasarkan pembahasan dan analisis serta kesimpulan tersebut diatas maka penulis bisa menyampaikan saran saran sebagai berikut:

1. Tindakan berikutnya yang harus direalisasikan adalah Pembetulan pada pengkalkulasian harga pokok produksi wajib dilakukan sesuai dengan teknik full costing dengan mengkalkulasi serta mengrekognisi beban bahan baku, biaya tenaga kerja langsung, serta biaya overhead pabrik yang harus menjadi pokok pemusatan khusus dari owner perusahaan guna memastikan harga pokok produksi yakni perpautan karakteristik dari metode full costing dan variabel costing ini.

2. Metode variabel costing disarankan penulis untuk perusahaan yang melakukan adaptasi yang berfokus pada volume penjualan, metode variabel costing sangat mendukung manajemen dalam perencanaan jangka pende, misalnya yaitu dalam perancangan harga jual khusus. 


\section{Journal of Sustainability Business Research (JSBR)}

Vol-1,Issue-1,Desember (JSBR)

\section{E-ISSN: 2746-8607}

http://jurnal.unipasby.ac.id/index.php/jsbr

3. Peragendaan ulang dan pengekangan biaya dapat dihasilkan dari pengkalkulasian harga pokok produksi dengan teknik variabel costing pada entitas yakni laporan laba rugi yang disajikan dengan teknik variabel costing yang juga berfungsikan alat bantu untuk manajer memutuskan kebijakan ketetapan yang terkait dengan alur hidup entitas misalnya digunakan sebagai dasar dalam melaksanakan evaluasi hubungan antara biaya, volume, serta laba (cost volum profit analysis). Laporan laba rugi dengan memakai metode full costing karena tidak adanya pemisahan antara biaya yang berkarakter tetap dan variabe selanjutnya dipakai sebagai acuan dasar dalam memfungsikan evaluasi CVP (cost volum profit analysis)

\section{KETERBATASAN PENELITIAN}

Peneliti telah membatasi penelitian ini pada variabel metode full costing dan metode variabel menjadi variabel bebas dan variabel laba bersih menjadi variabel terikat pada PT BHASKARA MADYA JAYA

\section{DAFTAR RUJUKAN}

Arikunto. (2015), Prosedur penelitian suatu pendekatan praktek. Jakarta: PT. Riseka Cipta.

Carter, William K dan M. F Usry, 2006, Akuntansi Biaya, Buku 1, Edisi Ketigabelas, Penerjemah: Krista, Jakarta: Salemba Empat

Dewi, Sofia Prima dan Septian Bayu Kristanto, 2016, Akuntansi Biaya, Jakarta: IN MEDIA

Dahlan, Ahmad, 2015.Definisi Sampling Serta Jenis Metode dan Teknik Sampling,[online],

(https://www.eurekapendidikan.com. Diakses pada tanggal 29 September 2019)

Ghozali, Imam. 2013.Aplikasi Analisis Multivariabel Dengan

Kismono, Gugup. (2001), Bisnis pengantar. Yogyakarta : BPFE

Haryoko, Sapto dan Iskandar. (2008). Metodologi penelitian pendidikan \& sosial (Kuantitatif \& Kualitatif). Jakarta :

Gaung Persada Press.

Sudjiono.(2010).Pengantar statistik pendidikan.Jakarta:PT Raja Grafindo Persada.

Sugiono.(2001).Metode penelitian kuantitatif dan kualitatif,dan R\&D.Bandung:CV ALFABETA. (2014).Metode penelitian kuantitatif dan kualitatif, dan R\&D.Bandung:CV ALFABETA (2016).Metode penelitian kuantitatif dan kualitatif, dan R\&D.Bandung:CV ALFABETA (2017). Metode penelitian kuantitatif dan kualitatif, dan R\&D.Bandung:CV ALFABETA

Usman,Husaini.(2016).Metodologi Penelitian.Jakarta:Bumi Aksara.

Mulyadi, 2012, Akuntansi Biaya, Yogyakarta: UPP STMI YKPN , 2016, Akuntansi Biaya, Edisi 5, Yogyakarta: Sekolah Tinggi IImu Manajemen YKPN

Rudiyanto, 2006, Pengantar Akuntansi, Jakarta: Erlangga 